\title{
The Effect of Religiosity on Youth Lifestyle
}

\author{
Zohreh Molapanah \\ Research Office Manager of Dr. Shariaty College \\ Email:zohrehmolapanah@yahoo.com
}

Doi:10.5901/jesr.2013.v3n3p361

\section{Abstract}

Parallel to the global development and modernity out comes, the religiosity of people, in terms of attitude to religion or in the style of religious acts, has had changes. Part of these changes is affected by peoples lifestyle. This research has been done to examine the effect of students lifestyles on their religiosity. In this research the comments of gidens, vethno, prichard and lensky has been used. The researches approach is a descriptive -scientific approach that has examined the issue in a survey methodology. Questionnaire and accidental cluster sampling from 298 students has been used in order to gain information. The information about lifestyle, life patterns, cultural consumption, taste, leisure and body management has been analyzed by the SPSS software. The research results suggest that body management has the most direct influence on religiosity cultural consumption has the most in direct influence.

Keywords: religiosity, aspects of lifestyle, life pattern, cultural consumption, body management.

\section{Introduction}

Today, religious scholaring in a scientific manner and acceptable methods in liberal arts is one of the newest and most putative research areas in scientific fields and academies. A lot of researches has been done about religion and its functions with different views. [1- Argyle M, Hallahmi B, 1975.]

You might be able to say that this era is the era of referring to religion and verification its concept, and the people of this century are known as religions people. Because referring to the latest researches in sociology more than 95 percent of people have believe in god.[2-Elyadh M,1374.Vdyn culture. Translated: Khoramshahi B .pp.54]

Measuring religiosity in Iran is one of the subjects which we can find the importance from the exuberance of efforts for making and using measuring tools for measuring religiosity in these years. These efforts come out from the needs and understandable necessity which cannot be left unanswered. The necessity generally is raised from the influence and reputation that religion has for human and the society.[3- Shojaeez A, 1382.A model for measuring religiosity in Iran, Iranian Journal of Sociology, Volume 6, 1: 34-66.]

Religiosity studies for societies like ours which religion has an effective influence on its surfaces has even more requirements.

Although religion and religiosity is one of the most important pillars of our society, and has influence on people and structure, but in the recent years changes in peoples religiosity has been spotted. Also along with the arrival of modernity and industries and the expanse of communication, basal changes has occurred in peoples traditional lifestyles.

Ina modern society, people can experience a new lifestyle, now they can freely choose from between many different choices.

A new lifestyle may affect the layers of people's lives including their religiosity.

The concept of lifestyle is one of the concepts so prevalent in social science, that some believe this concept has the capability of displacing many words and can more accurately remark the complex truth of acts and cultural and social views in the modern society, and also the lifestyle which mostly can be seen, descripted and measured in all of the ones acts, conflicts and communications with others and generally in the environment surrounding him, can be examined.

From this point of view, lifestyle is the evident, obvious and sensible part of a society. Lifestyle can be examined in free times, amusements, sexual acts, job interests, clothing, art interests, literature, sports, language and etc.

In this society due to lifestyle and belief changes peoples religiosity either in theory or act of religion, has been mutated.(according to former research results)(for example RaminHabibzadeh's research). People are not clog to acting religiously and their religious manners have changed.

The above, shows that lifestyle in today's society has an important role in each person's life, because of the strong 
bond it has between, consumption, personal and local identity, appearance of the power to specify and choose or at least gaining the feeling of freedom.

Due to knowing Iran as a religious society throughout scientific circles and almost all of the social researches done to measure the religiosity of Iranians confirm this allegation.

Theorem analyses claim that religiosity is one of the social variants mutated in changing societies. [4- Durkheim E, 1383. Elementary Forms of the Religious Life in Australian totemism. Translator: Baqrrprham.pp.81] Religiosity in Iran is not an exception.

In a wide look religion and lifestyle are part of culture *on a macro view, religion and life styles are the components of culture, so they work together. On a conceptual discussion, definition and characters of religion and life style shows that, it is possible to establish a relationship (casual type) between these two concepts, Because as the definition, the life style is a pattern of a general behavior which comes from the passions and preferences, and it influences the person's conceptualsystem, too.[5- MahdaviKani M S, 1387. Religion and Life Style.pp.187]

Stability will be conceived once all of the effective parts in shaping it are in a stable condition, and the slightest change in this process will mutate the whole.

Now we can understand that and change in lifestyle (either quantity or quality) will mutate religiosity.

We witness changes in youths and students lifestyles. So we must expect changes in their religiosity.in this research we are up to finding the effect of lifestyle on religiosity.

\subsection{Theoretical literature}

In the circle of religiosity and lifestyle researches with different approaches has been done that we will mention a few:

- Muhammad saiidmahdavikani, religion and lifestyle- case study of participants in a religious ceremony

- This thesis from a macro view is an effort for examining the role of religion in Iran's cultural-social evolution. This is a discovery research and first of all is relied on the meaning of religion and lifestyle and after that the description of the possible relationship between these two.

- Elhamrahmatabadi and habib agha bakhshi have done a research with the topic of lifestyle and the social identity of youths. The researches have gained the conclusion by using a quality method and the Delphi method.

- The conclude that nowadays youths more and less determine their choices and conditions instead of following a normal path leading to their traditional lifestyle.

- Although they believe society and family are still important since they are the basic fields that youths are raised in.

- $\quad$ aracie .h. boswal

- Arnold Michel has also researched about "worth and lifestyle".in this research American adults have been divided into different groups according to their lifestyles. Each type introduces a different approach to their life by connecting people's psychological needs to their acts.

Four general groups from Michel's model are:

1. The needful, those whom because of limited wealth sources, their lifestyle is based on their needs instead of choosing.

2. Those leaded from outside, those whom react to others real or fancy messages in their lives.

3. Those leaded from inside, those whom live by their own needs and interests.

4. Temperate ,those who have adapted being lead from inside and outside in their lives.

Anthony veil, has done a research under the topic of leisure, culture and lifestyle. The researcher has examined the relationship between leisure, level of culture and how lifestyles have shaped together in England.

Veil has studied the modern and postmodern points of view (about cultural studies and lifestyles), he concludes that effective structures such as social levels have kept their influence in shaping leisure acts.

He claims that most of the discords can still be specified by age, sex and social classification.

Age and sex and also social-economical parameters have considerable affects in crystalizing peoples lifestyles.

He shows that men in the ages $18-30$ are more active in sports clubs, more than women.[6- Veal A J, 1989.Leisure, lifestyle and status: A pluralist framework for analysis. Leisure Studies, Vol. 8, pp. 141-150.] 


\subsection{Offering a record}

In today's world all of us not only follow certain life methods but also in other words are ineluctable to follow. Actually we have no other choice but to choose so.

Lifestyle can be rendered as a collection of acts which one does. Because not only it covers his needs but also gives him identity in front of others. Also forces him to make decisions about what to wear, what to eat, what to do, how to leisure and how to be.[7- Giddens A, 1378. Sociology. Translated: spruce.pp.120]

In the field of work and any other fields for all the groups released from tradition, there are different choices for how to live, therefore different lifestyles between groups such as bordio stresses are actually intro structures for social layers and not an outcome from *In fact,structure formsarebasic for social packed layers. and not the "result" of differences in the realm of products. Thus Giddensbelieves choosing life style is associated with personal identities. Because in the modern world a person may face with a complex variety of possible choices that inevitably he has to choose amongst them. Consequently, choosing life style is important, although this choice is not always consciously.

From gidens point of view choosing a lifestyle is related to personal identity. Because in the modern world people face a complicated range of possibilities to choose and have to choose from among them. [8- Giddens A, 1378. Sociology. Translated: spruce: M.pp.121-142]

When the actives are in a university and in the time being (modern world) show new actions and major changes take place in their acts. And choose differently in these fields: life pattern, spend of free time tastes body management and etc. and generally in their lifestyle. With the shifts made in their life styles, the force shifts in other peoples acts swell and other acts are rebuilt, and the shifts made in their acts will lead to shifts in their religiosity.

prichard believes:" in examining americas change of religion in the past two centuries it will add up to : lifestyle issues such as Mari Juana, living together, and other personal freedoms has divided the country. The anti-cultural ideology that has grown out of hands to solve the social and political problems is now threatening the integration of religion."[9- Glock C Y, Bella R N. (Eds.), 1976. The Religious Consciousness. University of California Press.pp.328]

With the growing activities of anti-cultural groups who have new lifestyles and ideologies a new lifestyle raised in the society, as the new lifestyle spreads, peoples religions are threatened to change.

wethno believes :" by using the same pizza's elements, has examined new lifestyles in America, especially the movement called anti- culture. he concludes that this movement has put away a harsh part of tradition and religion and has given a new and unclear definition of religion. He believes this issue is not a simple reflex of religional dissatisfaction its actually a large wave of anti-culture and anti-society experience.

wethno has tried to explain many of the personal experience changes in lifestyles such as sexual freedom, using drugs, new religious acts and... In relation with competitor systems (especially religious ones). wethno claims the new systems competing old systems(same religion) are developed. These systems have made changes in the cognitive state of people, and these changes have made shifts in their cultural experiences and lifestyles.

Along with the new lifestyles produced by different movements, the religious systems begin to change for people and the old systems start to shift and a large part of these change are in peoples lifestyles.[10- Glock C Y, Bella R N. (Eds.), 1976. The Religious Consciousness. University of California Press.pp.279-292]

About why has to be studied but you might say the anti-cultural groups in west societies perhabs. These groups started a movement against the current culture such as religion. Social researchers named these movements as sub culturals and new lifestyles. Among these subcultures there were sects beside the churches or against them, suggesting new religions and lifestyles to their followers. Some of these researches are mentioned in the following. [11- MahdaviKani M S, 1387. Religion and Life Style.pp.206]

lenski by reffering to his own research in 1958 and the statics of the fifties in the massive city of Detroit in America tried to answer this question: do religional beliefs effect ones daily activities? Especially in a secular society such as America. Can a secular system be effected by religion? [12- Lenski G, 1963. The Religious Factor. New York: Anchor Book. Press.pp.1]

Lenski has pointed several remarks in his summary, which a few of them are related to religion and lifestyle.They include four groups of social-religious factors known as dignity -as a political factor-which has gotten importance increasingly in American society, and accordingly the importance of social classes - as the economical factor- and Ethnic groups- as a cultural factor - is decreasing.

In his summary, lenski examines Webbers point of view and as a Theoretical - Practical summary and believes there is two type of influence of religion on new societies: first, the direct effect of religion on social systems which he believes these effects are because of the leaders of the protest movements against some of the systems activities that 
these protests are in the shape of religion and of course most of them are left unfinished and this infertility leads to this claim that religion is not effective to new societies. And the second is the in directeffect on social systems. Therefore religion effects thousands or millions of its followers characters or acts. And this will effect the current systems in a long period of time. [13- Lenski G, 1963. The Religious Factor. New York: Anchor Book. Press.pp.173-369]

\subsection{Hypotheses}

Regarding the relationship between independent variables (taste, body management, consumer culture, life style) with the dependent variable religiosity, the analytical model is shown in the following hypothesis can be deduced

\subsubsection{The main hypothesis of the research: it seems that students lifestyle affects their religiosity.}

\subsubsection{Secondary research hypotheses}

Its seems cultural consumer affects students religiosity

Its seems taste affects students religiosity

Its seems pattern of life affects students religiosity

Its seems body management affects students religiosity

Its seems lifestyle affects students religiosity

\section{Research methods}

In The theoretical part of the research, the library (documental) method has been used for preparing the basis and theory structure of the research. And in the practical part we have used field methods to gain quantitative survey. So that we've gathered basic intel by using valid questionnaires. The unit of analysis is the individual (students).Cochran's formula was used to calculate sample size.298 people... The sample is now divided into classes based on student discipline and academic level is random.

\subsection{Reliability and validity:}

"To ensure content validity, using the methods of elite consensus and in consultation with experienced teachers of his suggestions were used." [15- AZkya M, 1381 .Sociology of Development.pp.500] Due to the high lifestyle of the theories proposed by theorists, factor analysis method was used to find a suitable model.

The first factor involves the consumption and lifestyle which we named the pattern of life. The second factor that involves management or unauthorized material body is eating the body and call management. The third factor includes lifestyle, financial, nutrition, and sports is called taste.

The fourth factor, which includes books, movies, internet, and music is called Cultural consumption.

\subsection{Trustworthiness and reliability}

In order to study the reliability in this assess the alpha croonbak test is used. Number of items: the pre test contained 189 questions that after the students answered the questions on the answer sheet the data added up to 214 questions. Scale homogeneity of the output depends on the student's lifestyle and religiosity is calculated by the spss software. The reliability and validity of the independent variables are Over $74 \%$ and the dependent variable is $88 \%$.

\subsection{Conceptual and operational definitions of dependent and independent variables}

Definition of the concept of religion and its components Religiosity means "religious endeavor, having the attitude and actions tend to influence individual"[15- Haro S Himmelfarb, "Measuring religious involvement" Social Forces Vol.53 No.4:606-61836]" religion determines the nature and impact so It requires the detection of inter-religious acts however its depth and intensity of effect and the trend of its changes are characteristics which obtain by psychologists and sociologists outer verification and hence practical-comparative methods are applied." (Same:36) "Religious people can be recognized from others by two signs or methods. one is the dependency and religion obedience, the other is his 
religious consequences and the trail of religiosity in his mind, heart, and individual and social acts. grehardlenskies main concern is examining these religious effects and religiosity on current life and Customary institutions".[16- Shojaeez A, 1382.A model for measuring religiosity in Iran, Iranian Journal of Sociology, Volume 6, 1: 35-63.]

Faith is belief in theoretical content that overviews to the fundamental subjects of ontology and Ultimate issues of life.

However the faith is the theoretical containment of belief. although the Inseparability makes it hard to access these aspects clearly, and makes defining one without the other, quietly impossible, but With emphasis on the key aspects of each of these two concepts its clearly shows that belief arises from the mind ant faith arises from the Psychological - Emotional aspect of human. This is understood that the first is closer to religion with a noetic approach and the second one with an emotional approach. The meaning of worship is all the behaviors person does in the presence of his (Idol) God. Good faith in the command and prohibition is called moralities and comes from good dealing with others.

Sharia is a set of explicit or implicit religious rules called jurisprudence in Islam-minus the worshiping rules-. Sharia are the least rules focusing on how to live, how to face yourself, environment and others, so the more people obey these rules the more acceptable they become.

\subsection{Operational definition of religiosity components: it has four indexes:}

1- Belief includes the principle laws and the branch laws

2- Sharia includes Duties taboos Mustahabat the Macro hat.

3-worship includes religious acts and ceremonies

4-morality includes obeying personal moral rules and social moral rules.

\subsection{Lifestyles concept definition and its components:}

"Vensel believes that lifestyle is the gathering of Norms and behavioral patterns that have been collected through the socialization of the individual. This implies that lifestyle is not only formed from behaviors but is also formed from peoples values and views. It could be said that lifestyle is a social issue that is based on the persons dealing between people, the social-cultural environment and also the physical surroundings. Therefore lifestyle includes both aspects of ones life either the objective or meaningful aspect. In general, the idea of life, trying to understand the interaction between the environment and the systems that is effective to ones mental development."[17- Azimi L, 1385. The Effects of Mass Media on the life style. PhD thesis.pp.55]

leisure: "in defining leisure it has been said: a set of business one does with complete satisfaction to rest or have fun or in means to Develop knowledge or acquisition of non-profit and community involvement, voluntarily attend to it after work , family and social business".[18- Shafie S, 1386. Gender Studies Leisure: Towards an explanation of life Iranian lifestyle patterns, Strategic Research Institute.pp.140-143]

body management: "chavooshian claims that different habits in haircuts, and the use of make up, management of Hygiene and health care are all part of body management."[19- Fazeli M, 1382. Consumption and Lifestyle.pp.128] The elements that zimel, weblen and weber have cited in their writings are: the type of eating, make up (clothing and mod) type of house (decoration, structure and furniture) type of vehicle, type of leisuring, germ (behaviors that stand for Noblesse oblige, spend thrift, smoking in public).

Taste: meaning: Desire, passion, love, pleasure and judgment. zimel defines taste as a capability to choose appropriate behaviors that one has to object.[20- MahdaviKani M S, 1387. Religion and Life Style.pp.60, 66]

Pattern of life: levid warner while examining Yankee cities lifestyle of leisure and recreation and sporting tastes has pointed to the differences between the religious and ethical perspectives, political values, patterns of life, marriage and raising children in his research.[21-James M, Introduction of Sociology, Holt Rinehart \& Winston Inc.pp.274-275]

lesley and others in a general point of view know lifestyle (such as taste in choosing wine, decoration, reading and spending time) as a pattern of life.

Cultural consumption: some of the types of cultural consumptions applied are: reading books, listening to music, acts of arts, surfing the net and watching television. Every cultural consumption can be used in a different aspect of ones life as an element.[22- Gerald L, Richard L, Benjamin G, Introductory Sociology, Oxford Un.Press.pp.27,370] 


\subsection{The operational elements of lifestyle:}

Independent variable in this study is lifestyle that in need to measure it due to the theoretical structure of this research the aspects of this meaning can be divided in to 5 aspects of leisure, body management, cultural consumptions, life pattern and taste afterwards we examined each lifestyle and cultural approach.

"Cultural lifestyle: the more the society reaches higher levels of economy, social levels, the more culture and peoples cultural life become important and studying peoples cultural lifestyle in cultural consumption stands with importance. Cultural consumption has led to cultural capital". [23- Fazeli M, 1382. Consumption and Lifestyle.pp.177]

As said the way to spend time, body management taste, life pattern, cultural consumption are the elements that constitute lifestyle in this project that we have briefly pointed to each one.

Leisure: sub-dimensions: leisure includes act of art and Cultural, reading and social communication.

Cultural consumption: it has 5 sub-dimensions: books, music, movies, internet, and art classes.

Taste: it has 5 sub-dimensions: costs, type of life, messages, sports and eating.

Body managements: it has 2 sub-dimensions: body management and drugs.

Life pattern: it has 2 sub-dimensions: choosing a mate and time consumptions.

\section{Results and Discussion}

First of all we examine the descriptive research findings.

Table1: Percentage distribution of students in religious

\begin{tabular}{|c|c|c|c|c|}
\hline religiosity & Frequency & Percent & $\begin{array}{c}\text { Valid } \\
\text { Percent }\end{array}$ & $\begin{array}{c}\text { Cumulative } \\
\text { Percent }\end{array}$ \\
\hline very weak & 11 & 3.7 & 4.5 & 4.5 \\
Weak & 17 & 5.7 & 6.9 & 11.3 \\
medium & 87 & 29.2 & 35.2 & 46.6 \\
Strong & 111 & 37.2 & 44.9 & 91.5 \\
Very strong & 21 & 7 & 8.5 & 100.0 \\
I respondents & 247 & 82.9 & 100.0 & \\
Missing & 51 & 17.1 & & \\
Total & 298 & 100 & & \\
\hline
\end{tabular}

According to the table above most of the students are amenable to medium, and a small percent of them are weak, very weak and very strong.

Table 2 :Percentage distribution of students in lifestyle

\begin{tabular}{|c|c|c|c|c|}
\hline lifestyle & Frequency & Percent & $\begin{array}{c}\text { Valid } \\
\text { Percent }\end{array}$ & $\begin{array}{c}\text { Cumulative } \\
\text { Percent }\end{array}$ \\
\hline very material & 32 & 10.7 & 19.2 & 19.2 \\
Material & 48 & 16.1 & 28.7 & 47.9 \\
Intermediate & 45 & 15.1 & 26.9 & 74.9 \\
Cultural & 28 & 9.4 & 16.8 & 91.6 \\
very cultural & 14 & 4.7 & 8.4 & 100.0 \\
I respondents & 167 & 56 & 100.0 & \\
Missing & 131 & 44 & & \\
Total & 298 & 100 & & \\
\hline
\end{tabular}

About the lifestyle that is the independent variable, the findings show that most students have a material very material and intermediate (going from material towards cultural) lifestyle, and a very small percent have a cultural and very cultural lifestyle.

In the second test, the main theory of the relationship between life style and religious study, the research will focus on the analytical finding which the Pearson coefficient was used. 
Table 3: Pearson correlation, style and dimensions of religiosity

\begin{tabular}{|c|c|c|c|c|c|}
\hline taste & belief & Sharia & worship & morality & religiosity \\
\hline Pearson correlation & ${ }^{*} 0.167$ & ${ }^{*} 0.216$ & 0.094 & 0.118 & ${ }^{*} 0.207$ \\
Sig. & 0.011 & 0.001 & 0.0140 & 0.67 & 0.003 \\
\hline
\end{tabular}

The results of the Pearson test, show that religious orientation and after that religion and belief have the most effect and worship and moral individuals will not have any effect on the individuals taste.

Table 4: Pearson correlation Designs and dimensions of religiosity.

\begin{tabular}{|c|c|c|c|c|c|}
\hline life pattern & belief & Sharia & worship & morality & religiosity \\
\hline Pearson correlation & ${ }^{* *} 0.167$ & ${ }^{*} 0.139$ & ${ }^{* *} 0.230$ & 0.064 & ${ }^{* *} 0.260$ \\
Sig. & 0.007 & 0.024 & 0.000 & 0.293 & 0.000 \\
\hline
\end{tabular}

The results of the Pearson test, show that religion and after that religious orientation and belief and worship have the most effect and moral individuals will not have any effect on the individuals lifestyle.

Table 5: Pearson correlation Designs and dimensions of body management with religiosity

\begin{tabular}{|c|c|c|c|c|c|}
\hline body management & belief & Sharia & worship & morality & religiosity \\
\hline Pearson correlation & $-0.178^{* *}$ & ${ }^{*} 0.155$ & $-0.347^{* *}$ & -0.115 & $-0.184^{* *}$ \\
Sig. & 0.007 & 0.019 & 0.000 & 0.078 & 0.008 \\
\hline
\end{tabular}

According to the conclusion in hands from pearsons test, worship then religiosity, body management belief have the most reverse effect on body management and religion has straight effect on body management and morality has no effect what so ever.

Table 6: Pearson correlation Designs and dimensions of cultural consumption with religiosity

\begin{tabular}{|c|c|c|c|c|c|}
\hline cultural consumption & belief & Sharia & worship & morality & religiosity \\
\hline Pearson correlation & ${ }^{*} 0.156$ & 0.112 & 0.063 & 0.039 & ${ }^{*} 0.177$ \\
Sig. & 0.022 & 0.099 & 0.344 & 0.564 & 0.013 \\
\hline
\end{tabular}

According to the conclusion in hands from pearsons test, religiosity then belief, have the most effect on cultural consumption and morality, worship and religion have no effect on cultural consumption.

\subsection{Examining the model}

In this study, stepwise multiple regression was performed that brings in the Independent variable, body management, life style and taste(because cultural consumptions variable had the meaning full level of 0/05\% it was put away in the regression) and the dependent variable was brought in instead.

Table 7: Table of coefficients

\begin{tabular}{|c|c|c|c|c|}
\hline Model & $\mathrm{R}$ & $\begin{array}{c}\mathrm{R} \\
\text { Square }\end{array}$ & $\begin{array}{c}\text { Adjusted } \mathrm{R} \\
\text { Square }\end{array}$ & $\begin{array}{c}\text { Std. Error of the } \\
\text { Estimate }\end{array}$ \\
\hline 1 & $0.386^{\mathrm{a}}$ & 0.149 & 0.134 & 14.136 \\
\hline
\end{tabular}

Table of regression the multivariate of religiosity and (management body, style, life style, cultural consumption) the coefficient of determination is $\mathrm{R}^{2}=0 / 149$ that the degree of religiosity variable, is explained by the independent variables. And also the adjusted coefficient of determination is equal to 0/386. 
Table 8: ANOVA

\begin{tabular}{|c|c|c|c|c|c|}
\hline Model & Sum of Squares & df & Mean Square & $F$ & Sig. \\
\hline Between Groups & 5779.853 & 3 & 1926.618 & 9.642 & 0.000 \\
Within Groups & 3290.064 & 165 & 199.819 & & \\
Total & 38749.917 & 168 & & & \\
\hline
\end{tabular}

Table F results: Regression analysis results indicate that the independent variables explain more of the variance in the dependent variable and is the potential waste.

According to the test table of $\mathrm{F}$ with a meaning full level sig $=0.00$ we can refrence to the next table to write the regression formula.

Table 8: regression, multivariate of religiosity (and body management, taste, life pattern)

\begin{tabular}{|c|c|c|c|c|c|}
\hline \multirow{2}{*}{ Model } & \multicolumn{2}{|c|}{$\begin{array}{c}\text { Unstandardized } \\
\text { coefficients }\end{array}$} & \multirow{2}{*}{$\begin{array}{c}\text { standardized } \\
\text { coefficients }\end{array}$} & T & Sig. \\
\cline { 2 - 4 } & Mean Square & df & Mean Square & & \\
\hline life pattern & 157.432 & 5.643 & & 27.897 & 0.000 \\
body & 0.435 & 0.174 & 0.191 & 2.497 & 0.014 \\
management & $0.492-$ & 0.140 & $0.266-$ & $3.509-$ & 0.001 \\
taste & 0.157 & 0.057 & 0.224 & 2.778 & 0.006 \\
\hline
\end{tabular}

Due to the varied cultural consumption and the significant level of 0/05 it has been dropped out of this part and will return to the regression formula in another part.

According to the results above, significant variables in the final column show management, life style, taste is significant and in this case, the standard expected not to write the regression equation is significant variables of the formula is as follows:

$Y=157.432+0.157$ (taste) -0.492 (body management) +0.435 (life pattern)

Value of the intercept (constant 157.432) is. Factor affecting the pattern of life is equal to 0.435

Shape 1: Research model

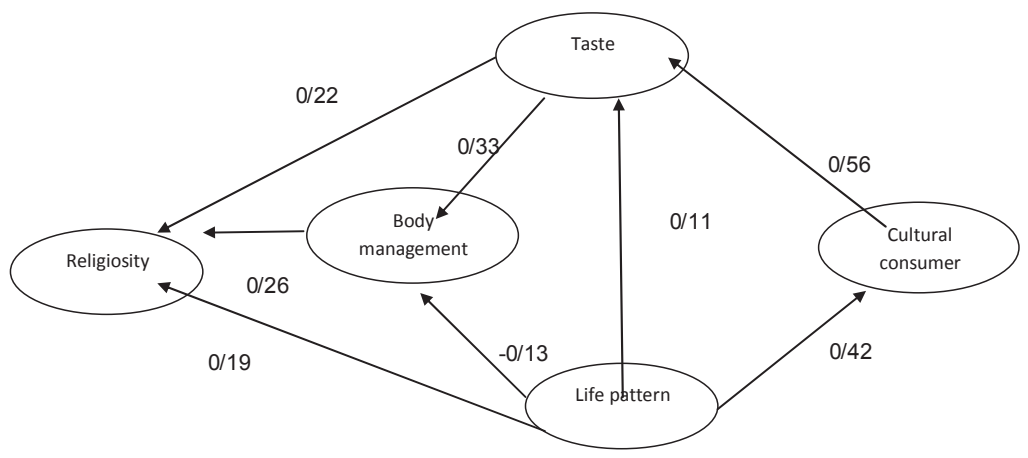

\section{Conclusion}

The finding of this research adds up to cultural lifestyle strengthens religiosity.

The more the students religiosity promotes the more cultural their lifestyle becomes. This means interaction of religion has a direct impact on culture and values, interests and lifestyle.

Students who are strongly religious follow a more materialistic life style. This fact shows that students have weak diagnosis in religion and also weakness in their believes about religious life being efficient in their lives and a kind of Inferiority complex towards religion that they follow, but don't have the needed recognition about Islam.

This actually shows the inward and outward character dichotomy of the students.

Most of the students who have strong religiosity have cultural views in their cultural consumptions. 
The trail of strong religiosity in cultural tastes shows good trust in self and individual personal taste.

The students who have strong religiosity have more cultural taste.

Practical adherence to religious and cultural influences on the tastes become more fully illustrate the nature and strength of character than others group of students.

The students more committed to Sharia are more committed to cultural tastes.

Commitment to belief also leads to better cultural taste, which has positive effects on Enhancement and the stability of the students character.

The more faithful the students are to religion the more cultural their body management will be.

Being faithful to the religion is the consequent of being in touch with the resale and spiritualties which has positive effection their culture management which we can clearly see.

The students strongly religious most of their body management is material. This concussion also shows that weakness in these students religional beliefs about efficacy of religion in their personal lives and being double charictaristic or personal needs is seen.

The students more Faithfull to their worship, have a more cultural life, worshiping leads to choosing a cultural life pattern.

The students more religious, have a more cultural life, the more strong they are in religious aspects they chooses a more cultural life pattern.

The students more Faithfull to Sharia, have a more cultural life, the more strong they are in religious aspects they have a better cultural life.

The more religious the students are the more cultural their life pattern is.

The more religious the students are the more they focus on culture in their cultural consumptions.

In cultural consumptions its more focused on culture and again the outter face of consumption.

The more religious the students are the more they focus on culture in their cultural consumptions.

Range of cultural consumption influences on student religiosity variables, the effect of cultural consumption on the religiosity of students is 0.177 . Choosing movies, music, books, internet and ... is effective on ones religiosity.

The variable of taste effects the students religiosity and its effect is 0.207 .

The variable of life pattern effects the students religiosity and its effect is 0.26 .

The variable of body management effects the students religiosity and its reverse effect is -0.184 .

Spending life, sports, nutrition, massage and how to live has a direct and high influence on ones life.

Time consumption and elements to choose a mate has a direct and high influence on ones life.

Body management and using drugs has a reverse and high influence on ones life.

In general taste has the most direct effect on students religiosity meaning the more cultural their taste is the more religious they are.

Body management has the most reverse effect on their religiosity.

Cultural consumption has the most indirect influence.

Different levels of education, where living, education level of the adults and different feild of education does not effect their religiosity.

\section{References}

AZkya M,1381 .Sociology of Development. Tehran: Word Publishing Institute.

Argyle M, Hallahmi B, 1975. The Social Psychology of Religion. London:University Press.

Azimi L, 1385. The Effects of Mass Media on the life style. PhD thesis, social groups ,Islamic Azad University, Vahdlvm and research,Tehran,Iran.

Durkheim E, 1383. Elementary Forms of the Religious Life in Australian totemism. Translator: Baqrrprham. Tehran: capital of publication.

Elyadh M,1374.Vdyn culture. Translated: Khoramshahi B, Tehran: new design.

Fazeli M, 1382. Consumption and Lifestyle. Tehran: published by the true dawn.

Giddens A, 1378. Sociology. Translated: spruce : M, Tehran: Publishing straw.

Glock C Y, Bella R N. (Eds.), 1976. The Religious Consciousness. University of California Press.

Himmelfarb H S ,1977.Measuring religious involvement:Social Forces Vol:53.4:606-618.

Khodapanahi MK, chiefs born Sryzdy, 1379. students examine the role of personality in religious orientation: Journal of Psychology. 14:25-28

Lenski G, 1963. The Religious Factor. New York: Anchor Book. 
Lenski G, 1963. The Religious Factor. New York: Anchor Book. Press.pp.1

Leslie G R, Larson R F, Gorman B L, 1994. Introductory Sociology. Oxford, Oxford Un.Press.

MahdaviKani M S, 1387. Religion and Life Style. Tehran: publication of Imam Sadegh

Mckee J B, 1969. Introduction of Sociology. Holt R, Winston I.

Shafie S, 1386. Gender Studies Leisure: Towards an explanation of life Iranian lifestyle patterns, Strategic Research Institute

Shojaeez A, 1382.A model for measuring religiosity in Iran, Iranian Journal of Sociology, Volume 6, 1: 34-66.

Veal A J, 1989.Leisure, lifestyle and status: A pluralist framework for analysis. Leisure Studies, Vol. 8, pp. 141-153.

James M, Introduction of Sociology, Holt Rinehart \& Winston Inc.pp.274-275

Gerald L, Richard L, Benjamin G, Introductory Sociology,Oxford, Oxford Un.Press.pp.27,370

Haro S Himmelfarb, "Measuring religious involvement" Social Forces Vol.53 No.4:606-61836

Argyle M, Hallahmi B, 1975. The Social Psychology of Religion. London:University Press.

Azimi L, 1385. The Effects of Mass Media on the life style. PhD thesis, social groups ,Islamic Azad University, Vahdlvm and research, Tehran, Iran.

AZkya M,1381 .Sociology of Development. Tehran: Word Publishing Institute.

Durkheim E, 1383. Elementary Forms of the Religious Life in Australian totemism. Translator: Baqrrprham. Tehran: capital of publication.

Elyadh M,1374.Vdyn culture. Translated: Khoramshahi B, Tehran: new design.

Fazeli M, 1382. Consumption and Lifestyle. Tehran: published by the true dawn.

Gerald L, Richard L, Benjamin G, Introductory Sociology,Oxford, Oxford Un.Press.pp.27,370

Giddens A, 1378. Sociology. Translated: spruce : M, Tehran: Publishing straw.

Glock C Y, Bella R N. (Eds.), 1976. The Religious Consciousness. University of California Press.

Haro S Himmelfarb, "Measuring religious involvement" Social Forces Vol.53 No.4:606-61836

Himmelfarb H S ,1977.Measuring religious involvement:Social Forces Vol:53.4:606-618.

James M, Introduction of Sociology, Holt Rinehart \& Winston Inc.pp.274-275

Khodapanahi MK, chiefs born Sryzdy, 1379. students examine the role of personality in religious orientation: Journal of Psychology. 14:25-28

Lenski G, 1963. The Religious Factor. New York: Anchor Book.

Leslie G R, Larson R F, Gorman B L, 1994. Introductory Sociology. Oxford, Oxford Un.Press.

MahdaviKani M S, 1387. Religion and Life Style. Tehran: publication of Imam Sadegh

Mckee J B, 1969. Introduction of Sociology. Holt R, Winston I.

Shafie S, 1386. Gender Studies Leisure: Towards an explanation of life Iranian lifestyle patterns, Strategic Research Institute

Shojaeez A, 1382.A model for measuring religiosity in Iran, Iranian Journal of Sociology, Volume 6, 1: 34-66.

Veal A J, 1989.Leisure, lifestyle and status: A pluralist framework for analysis. Leisure Studies, Vol. 8, pp. 141-153. 